УДК: 332.122.5

\begin{abstract}
МИТВИНЕНКО ИННА ЛЕОНТЬЕВНА
к.э.н., доцент, доцент кафедры управления и предпринимательства ФБГБОУИ ВО «Московский государственный гуманитарно-экономический университет», e-mail: innalitvinenko@yandex.ru
\end{abstract}

КАЗАНБИЕВА АИДА ХИЗРИЕВНА к.э.н., доиент, доиент кафедры информатики คЭУ им. Г.В. Плеханова, e-mail: aida_k74@mail.ru

ГАСАНОВА АИДА ДЖИГАНОВНА к.э.н., доцент, старший преподаватель кафедры 48, Военный университет Министерства обороны e-mail: jiganovna@mail.ru

\title{
ПРОЦЕССЫ ИННОВАТИЗАЦИИ И ЦИФРОВИЗАЦИИ НА РЕГИОНААЬНОМ УРОВНЕ В РОССИИ
}

\begin{abstract}
Аннотауия. Џель работы. В статье проведено исследование проиессов инноватизации и цифровизации на региональном уровне и предложены меры по их интенсификации. Метод или методология проведения работы. На основе исследования статистики результатов илифровизации и инноватизации в регионах рассматриваемые процессы охарактеризованы качественно и количественно, после чего на основе метода анализа разработаны авторские рекомендации по совершенствованию процессов цифровизации и инноватизации. Результаты. В статье предложен комплекс мер по интеграции усилий государства и системообразующих участников инновачионных региональных систем на основе использования современных иифровых технологий в проиессе управления производством и сферой услуг на региональном уровне. Выявлены ключевые препятствия для эффективной реализащии процессов циффовизащии и инноватизащии, характерные для современных региональных экономических отночений. Определены возможные направления устранения этих препятствий за счет совместной деятельности участников инновационных региональных систем с использованием цифровых технологий. Область прнменения результатов. Полученные по результатам анализа проиессов иифровизаиии и инноватизаиии на региональном уровне результаты могут быть использованы при разработке государственных программ инновационного развития как на региональном, так и на местном

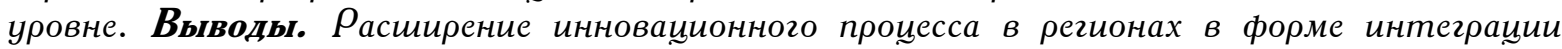
науиональных инновационных систем в общероссийское инновационное конкурентное пространство на основе использования цифровых технологий возможно и актуально как в среднесрочной, так и долгосрочной перспективе инновационного развития отечественной региональной экономики (экономики мезоуровня).
\end{abstract}

Ключевые слова: региональная экономика, инноватизаиия, человеческий капитал, реформы, интегращия, государственная поддержка регионов.

LITVINENKO INNA LEONTIEVNA

$\rho$ h. D. in Economics, associate $\rho_{\text {rofessor, Department of management }}$ and entrepreneurship, Moscow state University for the Humanities and Economics, e-mail: innalitvinenko@yandex.ru

KASANBIEVA AIDA KHIZRIEVA

Ph. D. in Economics, associate $\rho_{\text {rofessor, Department }}$ of computer science Plekhanov Russian University of Economics, e-mail:aida_k74@mail.ru 


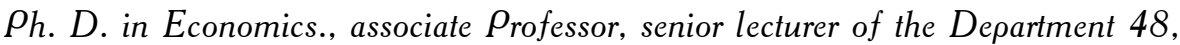
Military University of the Ministry of defense of the Russian Federation, e-mail: jiganovna@mail.ru

\title{
INNOVATION AND DIGITALIZATION PROCESSES AT THE REGIONAL LEVEL IN RUSSIA
}

\begin{abstract}
Purpose of work. The article studies the processes of innovation and digitalization at the regional level and suggests measures to intensify them. Method or methodology of the work. Based on the study of statistics on the results of digitalization and innovation in the regions, the processes under consideration are characterized qualitatively and quantitatively, after which, based on the analysis method, the author's recommendations for improving the processes of digitalization and innovation are developed. Results. The article offers a set of measures to integrate the efforts of the state and system-forming participants of innovative regional systems based on the use of modern digital technologies in the process of managing production and services at the regional level. The key obstacles to the effective implementation of digitalization and innovation processes that are characteristic of modern regional economic relations are identified. $\rho_{\text {ossible ways to eliminate these obstacles through joint activities of participants in innovative re- }}$ gional systems using digital technologies are identified. The scope of the results. The results obtained from the analysis of digitalization and innovation processes at the regional level can be used in the development of state programs for innovative develooment both at the regional and local levels. Conclusions. Expansion of the innovation process in the regions in the form of integration of national innovation systems into the all-Russian innovative competitive space based on the use of digital technologies is possible and relevant both in the medium and long term for the innovative development of the domestic regional economy (meso-level economy).
\end{abstract}

Keywords: regional economy, innovation, human capital, reforms, integration, state support for regions.

Введение. Вовлечение инновационного потенциала России в систему экономических отношений является одним из приоритетных направлений развития национальной экономики страны на 2020-2030 годы. Сбалансированное региональное развитие, включающее блок государственных (как федеральных, так и региональных) программ инновационного развития, является одним из приоритетов, указанных на официальном российском портале государственных программ: https://programs.gov.ru/. Кроме того, вопросам инновационной ориентации экономического регионального развития уделяется существенное внимание в ряде документов федерального уровня, определяющих экономическое развитие страны на среднесрочную перспективу, в том числе в Послании Президента РФ Федеральному собранию, Прогнозе социальноэкономического развития России до 2036 года.

Региональный уровень экономических отношений занимает особое место с точки зрения формирования единого национального информационного пространства. С одной стороны, сбалансированное развитие региональной инновационной системы за счет расширения цифрового сопровождения в текущих экономико-инфраструктурных условиях в России требует существенно больших затрат, чем мегаполис-центрическое развитие. С другой стороны, приемлемое с точки зрения целей долгосрочного развития национальной экономики страны по структурным и временным параметрам раскрытие регионального инновационного потенциала регионов возможно преимущественно за счет цифрового компонента, что делает подобные затраты оправданными.

Методы исследования. В основу проведенного исследования положен метод анализа территориально-экономических показателей развития регионов страны. Исследованы представленные в официальной региональной статистике параметры инновационного развития укрупненных региональных территорий, выявлены связи между показателями развития и использования цифровых технологий и инновационным развитием на уровне региона. В целях повышения наглядности предлагаемых выводов в ходе их аргументации авторы использовали кар- 
тографические анаморфозы. Представленный в статье анализ включает также оценку зарубежного опыта решения поставленных в статье задач активизации процессов цифровизации и инноватизации на региональном уровне.

Оценивая текущее состояние инноватизации производства на уровне экономик регионов, можно констатировать следующее.

Процесс внедрения инновационных технологий в структуру регионального производства проходит менее интенсивно, нежели в столице и крупнейших российских мегаполисах. Недостаточно интенсивное формирование условий для инновационного развития в отечественных регионах снижает их конкурентоспособность в качестве территорий локализации национальных инновационных производств и приводит к расщеплению единого национального инновационного пространства, что, в свою очередь, затрудняет коммерциализацию инновационного потенциала регионов, в том числе человеческого потенциала [3]. Экспертная оценка текущего состояния инновационного развития регионов по критерию присутствия на их территории инновационных производств, соответствующих запросам глобального инновационного бизнеса по параметрам качества инновационной продукции и критерию инфраструктурного соответствия глобальному конкурентному процессу, представлена на рисунке 1.

Исследование представленной на рисунке 1 инфографики указывает на асимметричность инновационного развития регионов России с концентрацией проблем инновационного отставания на юге и востоке страны.

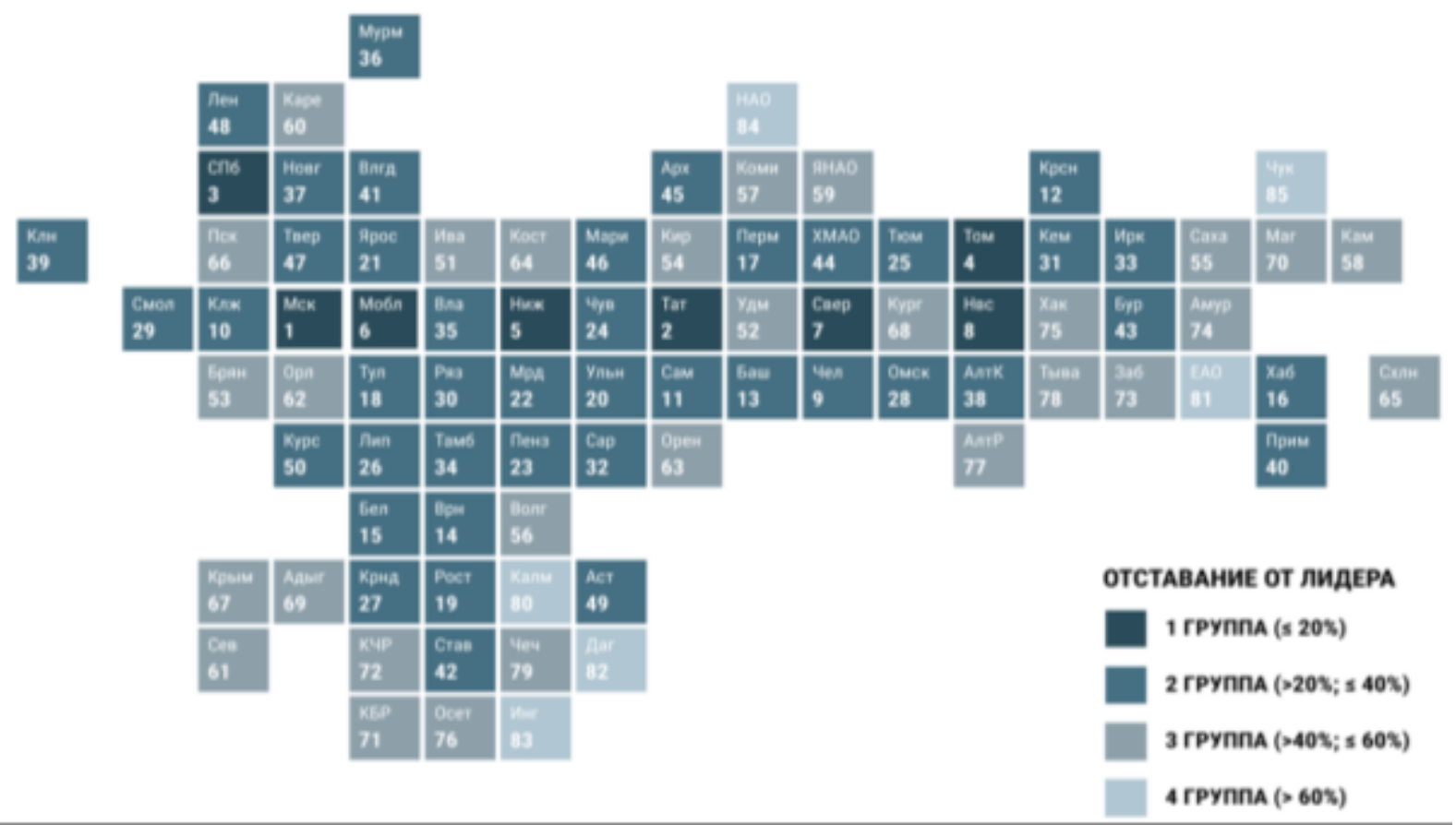

Pис. 1. Оченка состояния инновационного развития регионов России по критерию значения индекса инновачионного развития: географическая анаморфоза.

Источник: Рейтинг инновационного развития субъектов Российской Федерации. 6 выпуск. - М.: ИСИЭЗ, - 2019.

Исследование параметров, по которым асимметричность инновационного развития регионов в начале 2020 года оставалась наиболее высокой, позволяет выявить следующие критические позиции:

- асимметричность инфраструктурного развития регионов, связанная с асимметричностью распределения бюджетных доходов в рамках консолидированного бюджета России;

- асимметричность показателей концентрации в регионах представителей инновационного бизнеса, являющихся системообразующими с точки зрения глобальных инновационных процессов;

- показатели оттока наиболее подготовленных специалистов из регионов, а также показатели соответствия концентрации научных и образовательных учреждений запросам региональ- 
ной инновационной системы;

- соответствие инновационного климата в регионах запросам инноваторов - потенциальных резидентов данных регионов [7].

Отдельной проблемой, имеющей преимущественно институциональный, а не экономический характер, следует указать различия в уровнях доверия бизнеса инновационным системам в различных регионах, что также приводит к избыточной концентрации потенциальных инвестиций в инновационный процесс в Москве и крупнейших российских мегаполисах за счет их оттока из остальных регионов [12].

Вместе с тем в период 2010-2020 годов за счет целенаправленного воздействия на инновационный климат в регионах страны удалось обеспечить географическую децентрализацию потенциальных полюсов роста региональных инновационных систем. Географическая структура топ-20 российских регионов по критерию показателя индекса готовности к будущему, рассчитанному НИУ ВШЭ, представлена на рисунке 2.

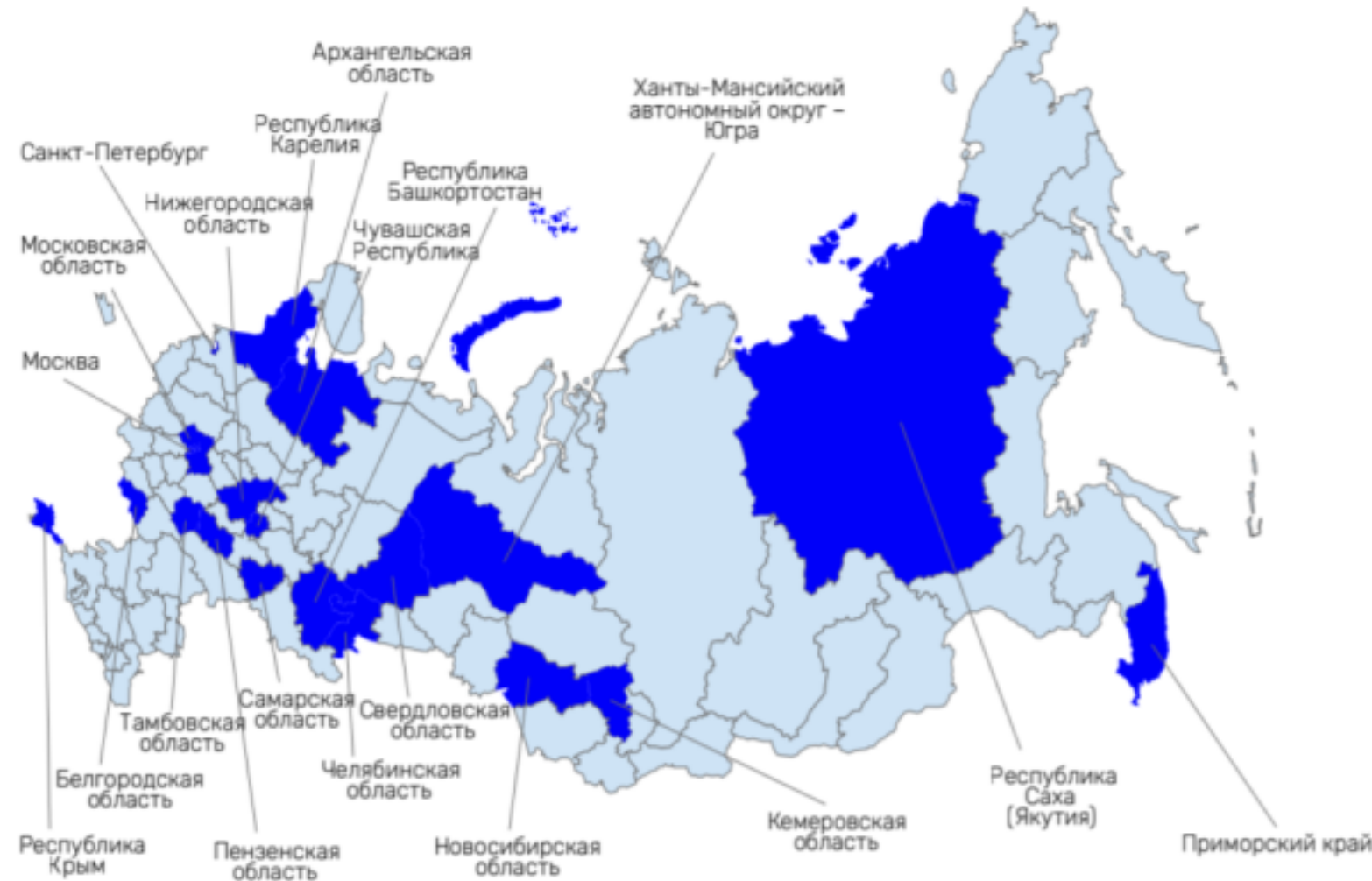

Puc. 2. Территориальное распределение топ-20 российских регионов по критерию оценки показателя индекса готовности к будущему, 2019 год.

Источник: Кузминов И. Рейтинг готовности регионов к будущему. - М.: НИУ ВШЭ, 2019.

В период 2020-2030 годов приоритетными задачами, стоящими перед органами государственной власти, ответственными за оптимизацию инновационного климата в регионах России и их реинтеграцию в единую национальную инновационную систему, являются:

- актуализация инновационного потенциала успешных региональных инновационных кластеров для максимального числа потенциальных участников региональных инновационных отношений;

- формирование положительного образа российского региона как потенциального реципиента инвестиций в инновации за счет раскрытия его инновационного потенциала и повышения транспарентности протекающих в нем экономических процессов и принимаемых на региональном уровне решений в области формирования инновационного регионального климата;

- перераспределение части человеческих и финансовых ресурсов инновационных компаний, как частных, так и имеющих формат государственных корпораций, в пользу региональных инновационных систем [8]; 
- обеспечение выхода региональных инновационных систем в глобальное информационное и конкурентное пространство;

- повышение эффективности и прозрачности использования средств федерального бюджета, направляемых на поддержку инновационного процесса в регионах.

Обзор представленных выше задач, стоящих перед Россией в 2020-2030 годах, позволяет утверждать, что значительная их часть требует решения в плоскости управления информационными процессами и национальным информационным пространством в целом. Наиболее значимым инструментом такого управления является использование цифровых технологий. Потенциал цифровизации как катализатора инновационного процесса на региональном уровне в экономике России может быть использован в следующих формах:

- вовлечение на базе развития информационно-коммуникационных связей максимального количества региональных потенциальных инноваторов в инновационный процесс вне зависимости от текущей его географической локализации [13];

- распределение части инновационных и производственных процессов, локализованных в 2020 году в крупнейших российских мегаполисах, в регионы, в том числе за счет использования резерва экономии организациями на разнице стоимости вовлекаемых в инновационный процесс ресурсов в крупнейших мегаполисах и регионах;

- доведение показателей эффективности региональных производственных и инновационных процессов до величин, требуемых на национальном и глобальном уровне, за счет перевода части производственных и бизнес-процессов в цифровой формат [16].

Приведенные выше рекомендации по интенсификации регионального инновационного процесса на базе использования цифровых технологий разработаны на основе обзора практики цифровизации и инноватизации экономики в регионах, ставшими в 2010-2020 годах альтернативными г. Москве и Санкт-Петербургу площадками инновационного развития. Изучение опыта Республики Саха (Якутия), Приморского края и Свердловской области, а также Тюменской области и Республики Татарстан указывает на значимость в региональном инновационном развитии качественного параметра.

Так, обобщение опыта инновационного развития рассмотренных пяти регионов позволяет утверждать, что наиболее успешными проектами по инноватизации региональных экономикопроизводственных процессов являются те, которые реализовывались на соответствующей запросам глобального инновационного рынка инфраструктурной базе. Наблюдается прямая корреляция между качеством организационно-инфраструктурного сопровождения процессов инноватизации и цифровизации в точках регионального экономического роста, с одной стороны, и результатами функционирования соответствующих точек роста с другой [1].

Для технопарков, локализованных в депрессивных регионах России и по этой причине испытывающих проблемы с первоначальными инфраструктурными инвестициями, результативность функционирования оказывается в 3-7 раз ниже, чем для технопарков, функционирующих в условиях оптимизированного инфраструктурного окружения.

Следует отметить, что география регионов России с максимальным финансированием совпадает с географическим поясом ведущих в смысле благоприятности инновационноинвестиционного климата регионов России в 2020 году, как показано на рисунке 3.

Вместе с тем ужесточение конкуренции на глобальном инновационном рынке не дает основание предлагать модель успешных в смысле инноватизации экономических процессов регионов [5].

Примерами подобных регионов являются Москва, Московская область, Якутск, Казань и ряд других регионов для заимствования в ранее используемом виде.

Действительно, текущая ситуация на глобальном инновационном рынке характеризуется:

- чрезмерной насыщенностью этого рынка и доминированием крупных регионально организованных производителей, имеющих возможность жесткого воздействия на новых региональных конкурентов из регионов России [18];

- контролем транснационального бизнеса над значительной частью как транснациональной, так и национальной составляющей инновационного процесса;

- разделением труда в инновационной сфере на основе регионально-географической принадлежности участников, например Тайвань контролирует технологии и физическое производство более 85 \% манипуляторов «мышь». 


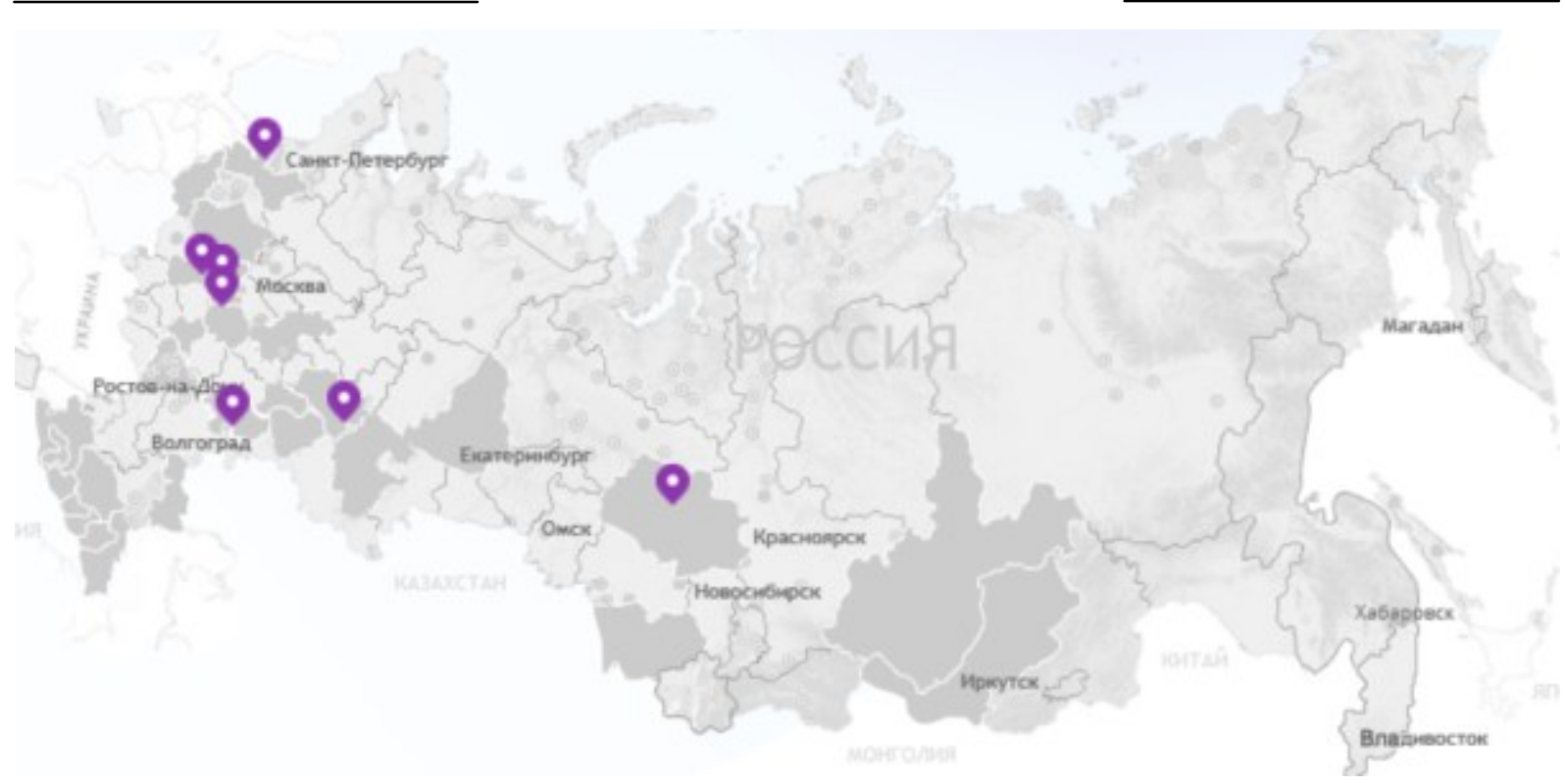

Pис. 3. География особых технико-внедренческих зон России, получивших преимущественное финансирование в 2010-2020 годах.

Источник: составлено по данным официального сайта ООО ОЭЗ: http://www.russez.ru/.

В сложившихся условиях выход нового регионального производителя в качестве участника глобального инновационного процесса на существующие рынки затруднен, в то время как сохранение его в качестве сугубо регионального участника инновационного процесса за счет протекционистских мер представляется экономически не оправданным.

Наряду с перечисленными обстоятельствами возможно выделить резервы инновационного роста региональных центров экономического развития за счет использования ими передовых цифровых технологий в соответствии с моделью опережающего развития.

В условиях модернизации глобальной трансформации международных цепочек добавленной стоимости и нарастания геоэкономических противоречий между Китаем, США и иными центрами инновационного развития индустриального общества снижается инвестиционная привлекательность действующих лидеров глобального инновационного процесса. Это дает России как обладателю значительного регионально- логистического потенциала возможность интеграции в соответствующие цепочки на условиях, актуальных как для представителей национального регионального бизнеса, так и транснационального бизнеса [11].

В сложившихся условиях возрастает значение готовности российских регионов к участию в транснациональных инновационных отношениях. Первоочередное значение при этом приобретает цифровое соответствие инфраструктуры этих регионов, обеспечивающее решение следующих вопросов:

- максимально оперативное включение региональных инноваторов в национальный и глобальный инновационный процесс на основе коммерциализации их инновационного потенциала и использования конкурентных преимуществ, таких как более низкая стоимость квалифицированной рабочей силы, наличие собственных профильных вузов и НИИ, значимых для данного инновационного процесса ресурсов [9];

- полнота представления конкурентного потенциала каждого из участников региональных экономических отношений в качестве потенциальных международных партнеров текущих лидеров глобального инновационного рынка [14].

Для соблюдения указанных выше условий безбарьерного вовлечения потенциала инновационного развития регионов в глобальный инновационный процесс за счет использования потенциала цифровизации авторы предлагают следующие шаги:

1. Актуализация человеческого, ресурсного и производственного потенциала возможного регионального инноватора в глобальном информационном пространстве; для этих целей перспективным видится расширение деятельности органов, ответственных за информационное 
развитие национальной экономики, в первую очередь Министерства цифрового развития, связей и массовых коммуникаций РФ, в направлении расширения коммуникационных связей регионов и глобального инновационного рынка [20];

2. Повышение качества связи и обеспечение ее доступности для потенциальных участников инновационного процесса в регионе; представляется целесообразным расширение практики предоставления налоговых и финансовых льгот инноваторам, сфера экономических интересов которых локализована в дотационных регионах страны.

На рисунке 4 представлены четыре группы параметров качества цифровых технологий, которые будут определять инновационный климат в российских регионах в 2020-2030 годах.

Следует отметить, что, хотя по показателям охвата сетью интернет и базовыми сервисами и качеству их работы российские регионы и приблизились к московским показателям в 2010 2020 годов, по-прежнему сохраняются проблемы обеспечения информационной безопасности, надлежащего финансово-административного процесса цифровизации экономических процессов на региональном уровне.

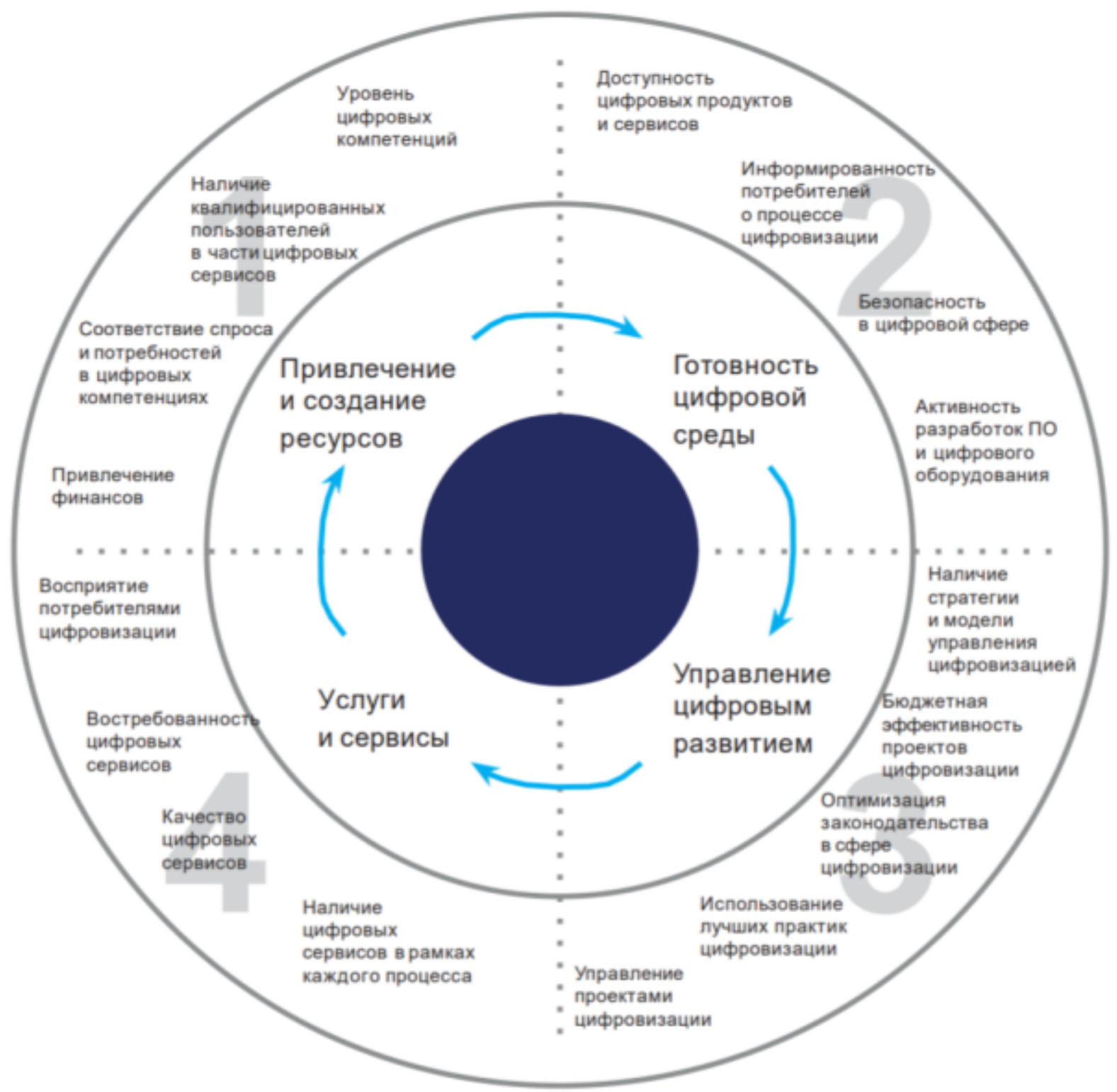

Pис. 4. Приоритетные направления развития информационно-коммуникационных технологий 8 регионах в иелях совершенствования их инновачионного климата на период 2020-2030 годов.

Источник: составлено на основе Дуненкова Е. Н., Онищенко С. И. Современные тренды и перспективы инновационного развития регионов в условиях цุифровизации // Modern Economy Success. - 2020. - № 3. - C. 153-158. 
При этом данная проблема имеет не столько технологическую, сколько экономикоинституциональную природу. Она проистекает из отсутствия скоординированной политики продвижения регионального инновационного потенциала на национальный и глобальный рынки.

Решение этой проблемы видится в создании дискуссионной площадки, актуальной для всех заинтересованных участников по критерию ее доступности, в том числе для малых региональных инновационных предприятий.

Результаты. В статье предложен комплекс мер по интеграции усилий государства и системообразующих участников инновационных региональных систем на основе использования современных цифровых технологий в процессе управления производством и сферой услуг на региональном уровне. Выявлены ключевые препятствия для эффективной реализации процессов цифровизации и инноватизации, характерные для современных региональных экономических отношений. Определены возможные направления устранения этих препятствий за счет совместной деятельности участников инновационных региональных систем с использованием цифровых технологий.

Выводы. Таким образом, расширение инновационного процесса в регионах по форме интеграции национальных инновационных систем в общероссийское инновационное конкурентное пространство на основе использования цифровых технологий возможно и актуально как в среднесрочной, так и долгосрочной перспективе инновационного развития отечественной региональной экономики (экономики мезоуровня).

\section{Литература}

1. Litvinenko I. L., Arefev P. V., Kriklivaya M. G., Solovykh N. N., Smirnova I. Human potential in the context of clusterization of russian economy // DILEMAS Contemporáneos: educación, politica y valores. 7. 2. 2020. 134 eISSN: 2007-7890

2. Litvinenko I. L., Smirnova I. A., Solovykh N. N., Aliev V. M., Li A. S. The fundamentals of digital economy // AD ALTA: Journal of Interdisciplinary Research. 2019 T. 9. No. 1. S 7. P. 30-37. eISSN: 1804-7890

3. Timokhin D. V., Putilov A. V., Pimenova V. O. Infrastructural support of the IT economy of Russia and ways to improve it // Procedia Computer Science. Vol. 145, 2018. P. 20-29. [An electronic resource]. Access mode: https://doi.org/10.1016/j.procs.2018.11.004, free. Heading from the screen.

4. Бугаенко М. В., Тимохин Д. В. Инноватизация производства - обеспечение конкурентоспособности отечественной металлургии // Цветные металлы. - 2012. - № 12. - C. 11-15.

5. Дуненкова Е. Н., Онищенко С. И. Современные тренды и перспективы инновационного развития регионов в условиях ичифровизации // Modern Economy Success. - 2020. - № 3. - C. 153-158.

6. Земиев С. П., Баринова В. А., Семенова Р. И. Государственная поддержка высоких технологий и инновачий в России // Инновачии. - №3. - 2019. - С. 40.

7. Кондаурова И. А., Цыбульник А. С. Инновации как основа развития регионов нового освоения / Инновационные перспективы Донбасса Материалы 4-й Международной научно-практической конферениии. - Донеик: ДНТУ, 2018. - С. 222-227.

8. Кузминов И. Рейтинг готовности регионов к будущему. - М.: НИУ ВШЭ, 2019.

9. Морковкин Д. Е., Строев П. В., Шапошников А. И. Финансовая поддержка регионов как инструмент выравнивания бюджетной обеспеченности субъектов Российской Федеращии. Финансы: теория и практика. - 2019; 23(4):57-68.

10. Нижегородиев Р. М. Инновации как источник роста российских регионов: институциональные фильтры и барьеры // Экономика и управление: теория и практика. - 2018. - T. 4. - № 1. - C. $72-77$.

11. Офиџиальный сайт ООО ОЭЗ. [Электронный ресурс]. Режим доступа: http://www.russez.ru/, свободный. - Загл. с экрана.

12. Регионы России. Социально-экономические показатели. - М.: Росстат, 2019.

13. Рейтинг инновачионного развития субъектов Российской Федераиии. 6 выпуск. - М.: ИСИЭЗ, 2019.

14. Рейтинг инноваџионных регионов России: версия 2019. - М.: Ассоџиаџия инноваџионных регионов России, 2018.

15. Смирнова Т. В. Регион как пространственная база реализациии инноваций // Стратегии бизнеса. 2019. - № 2 (58). - C. 15-17.

16. Субхангулов Р.Р. К вопросу о формировании и развитии инновациионного потенциала региона // Московский экономический журнал. - 2018. - № 5-2. - С. 27.

17. Суховей А. Ф., Голова И. М. Дифференциация стратегий инновационного развития с учетом специфики российских регионов // Экономика региона. - 2019. - T. 15, вып. 4. - C. 1294-1308. [Электронный ресурс]. Режим доступа: https://doi.org/10.17059/2019-4-25, свободный. - Загл. с экрана.

18. Татенко Г. И. Методы регионального форсайт-исследования в концепџии «умной специиализаџии» // Кластеризация цифровой экономики: Глобальные вызовы. Сборник трудов национальной научнопрактической конференции с зарубежным участием. - М.: МГУ, 2020. - С. 482-49.

19. Тимохин Д. В. Цифровизация экономики: современное состояние, проблемы и перспективы развития в России // Человек. Общество. Инклюзия. - 2018. - № 3 (35). - С. 57-66. 
20. Филиппов Д. В. Инновациинная деятельность как предмет экономического анализа // Модели, системы, сети в экономике, технике, природе и обществе. - 2018. - № 3(27). - C. 71-8.

\section{References:}

1. Litvinenko I. L., Arefev P. V., Kriklivaya M. G., Solovykh N. N., Smirnova I. Human potential in the context of clusterization of russian economy // DILEMAS Contemporáneos: educación, política y valores. 7. 2. 2020. 134 eISSN: 2007-7890

2. Litvinenko I. L., Smirnova I. A., Solovykh N. N., Aliev V. M., Li A. S. The fundamentals of digital economy // AD ALTA: Journal of Interdisciplinary Research. 2019 T. 9. No. 1. S 7. P. 30-37. eISSN: 1804-7890

3. Timokhin D. V., Putilov A. V., Pimenova V. O. Infrastructural support of the IT economy of Russia and ways to improve it // Procedia Computer Science. Vol. 145, 2018. P. 20-29. [An electronic resource]. Access mode: https://doi.org/10.1016/j.procs.2018.11.004, free. Heading from the screen.

4. Bugaenko M. V., Timohin D. V. Innovatizaciya proizvodstva - obespechenie konkurentosposobnosti otechestvennoj metallurgii // Cvetnye metally. - 2012. - № 12. - S. 11-15.

5. Dunenkova E. N., Onishchenko S. I. Sovremennye trendy i perspektivy innovacionnogo razvitiya regionov $v$ usloviyah cifrovizacii // Modern Economy Success. - 2020. - № 3. - S. 153-158.

6. Zemcev S. P., Barinova V. A., Semenova R. I. Gosudarstvennaya podderzhka vysokih tekhnologij $i$ innovacij $v$ Rossii // Innovacii. - №3. - 2019. - S. 40.

7. Kondaurova I. A., Cybul'nik A. S. Innovacii kak osnova razvitiya regionov novogo osvoeniya / Innovacionnye perspektivy Donbassa Materialy 4-j Mezhdunarodnoj nauchno-prakticheskoj konferencii. - Doneck: DNTU, 2018. - S. 222-227.

8. Kuzminov I. Rejting gotovnosti regionov k budushchemu. - M.: NIU VSHE, 2019.

9. Morkovkin D. E., Stroev P. V., SHaposhnikov A. I. Finansovaya podderzhka regionov kak instrument vyravnivaniya byudzhetnoj obespechennosti subëktov Rossijskoj Federacii. Finansy: teoriya i praktika. - 2019; 23(4):57-68.

10. Nizhegorodcev R. M. Innovacii kak istochnik rosta rossijskih regionov: institucional'nye fil'try i bar'ery // Ekonomika i upravlenie: teoriya i praktika. - 2018. - T. 4. - № 1. - S. 72-77.

11. Oficial'nyj sajt OOO OEZ. [Elektronnyj resurs]. Rezhim dostupa: http://www.russez.ru/, svobodnyj. - Zagl. s ekrana.

12. Regiony Rossii. Social'no-ekonomicheskie pokazateli. - M.: Rosstat, 2019.

13. Rejting innovacionnogo razvitiya subëktov Rossijskoj Federacii. 6 vypusk. - M.: ISIEZ, 2019.

14. Rejting innovacionnyh regionov Rossii: versiya 2019. - M.: Associaciya innovacionnyh regionov Rossii, 2018.

15. Smirnova T. V. Region kak prostranstvennaya baza realizacii innovacij // Strategii biznesa. - 2019. - № 2 (58). - S. $15-17$.

16. Subhangulov R.R. K voprosu o formirovanii i razvitii innovacionnogo potenciala regiona // Moskovskij ekonomicheskij zhurnal. - 2018. - № 5-2. - S. 27.

17. Suhovej A. F., Golova I. M. Differenciaciya strategij innovacionnogo razvitiya s uchetom specifiki rossijskih regionov // Ekonomika regiona. - 2019. - T. 15, vyp. 4. - S. 1294-1308. [Elektronnyj resurs]. Rezhim dostupa: https://doi.org/10.17059/2019-4-25, svobodnyj. - Zagl. s ekrana.

18. Tatenko G. I. Metody regional'nogo forsajt-issledovaniya v koncepcii «umnoj specializacii» // Klasterizaciya cifrovoj ekonomiki: Global'nye vyzovy. Sbornik trudov nacional'noj nauchno-prakticheskoj konferencii s zarubezhnym uchastiem. - M.: MGU, 2020. - S. 482-49.

19. Timohin D. V. Cifrovizaciya ekonomiki: sovremennoe costoyanie, problemy i perspektivy razvitiya $v$ Rossii // CHelovek. Obshchestvo. Inklyuziya. - 2018. - № 3 (35). - S. 57-66.

20. Filippov D. V. Innovacionnaya deyatel'nost' kak predmet ekonomicheskogo analiza // Modeli, sistemy, seti v ekonomike, tekhnike, prirode i obshchestve. - 2018. - № 3(27). - S. 71-8. 